\title{
¿CÓMO DIALOGAR CON SU PROPIA OBRA? AUTOTEMATISMO Y PRÉSTAMOS TEMÁTICOS EN LA TRADUCCIÓN LITERARIA
}

\begin{abstract}
Kasperska Iwona, ¿Cómo dialogar con su propia obra? Autotematismo y préstamos temáticos en la traducción literaria [How the author does maintain the dialogue with his own creation? Autotopicalisation and borrowings in literary translation]. Studia Romanica Posnaniensia, Adam Mickiewicz University Press, Poznań, vol. XXXVI: 2009, pp. 193-204. ISBN 978-83-232-2035-0. ISSN 0137-2475.

The aim of this paper is to show two particular cases of intertextual relations between different texts of the same author and these we find inside the same text. Both kinds of intertextual connections are illustrated with examples from the novels of the Cuban writer Manuel Cofiño and their translations into Polish.
\end{abstract}

\section{INTRODUCCIÓN}

La complejidad del fenómeno literario que es la intertextualidad, nos lleva a los teóricos y prácticos de la traducción a indagar sobre el grado de traducibilidad de este tipo de dependencia textual o sobre las estrategias que hay que emprender en el proceso de traducción de textos literarios muy intertextuales. Las dificultades nos acompañan en cada etapa del proceso que empieza con la desverbalización del texto original y la tarea resulta aun más complicada cuando ésos están muy vinculados con los llamados textos-arquetipos poco conocidos o desconocidos por completo en la cultura de llegada.

Numerosos estudios dedicados a la intertextualidad, sus definiciones y la terminología multiplicada por sus teóricos, muestran que ésta tiene múltiples facetas y se puede manifestar en distintos niveles del texto. Otros desvelan las dificultades del desciframiento de relaciones intertextuales y subrayan la importancia del papel del lector en dicho proceso. En el marco de este artículo que retoma un problema particular y puntual por excelencia, nos interesan dos casos particulares del dia- 
logismo que los autores mantienen con su propia obra literaria. Se trata de los vínculos temáticos y estructurales en el nivel de la misma obra y entre varios textos escritos por el mismo autor.

El hecho de que la intertextualidad carezca de una sola definición y sus líneas divisorias permanezcan fluidas, hace necesario que precisemos el espacio intertextul en el que nos vamos a mover y que definamos el tipo de dependencia entre textos que tomamos en consideración.

Los tipos de relaciones intertextuales que constituyen el núcleo de nuestro análisis fueron clasificados por Jean Ricardou como intertextualidad restringida, o sea, la que se refiere a otras obras del mismo autor, e intertextualidad interna, es decir, la que concierne a una relación del texto consigo mismo (Dällenbach, 1997: 87). Encontramos interesantes casos de ambos tipos de intertextualidad en la obra del autor cubano, Manuel Cofiño, cuyas novelas y sus traducciones al polaco constituyen el corpus de este artículo.

Antes de pasar al análisis es indispensable subrayar que vamos a usar la terminología de Gérard Genette que llama el hipertexto al texto que contiene relaciones con textos anteriores respecto a los cuales el teórico francés usa el nombre de hipotextos (Genette, 1997: 57).

\section{INTERTEXTUALIDAD RESTRINGIDA: PRÉSTAMOS TEMÁTICOS}

Cuando la sangre se parece al fuego es la segunda novela de Manuel Cofiño, publicada en 1975, y traducida al polaco por Maria Dembowska (Kiedy krew podobna jest do ognia, 1977). Dos de los principales ejes narrativos de esta obra los constituyen el cuento "Y por última vez", proveniente del libro Tiempo de cambio (1969), y el relato "Donde ahora crece un framboyán", también escrito anteriormente. El primero es un monólogo de Cristino Mora que visita su antigua casa, ahora clausurada, en la que transcurrió su infancia, y otro cuenta la historia de un hombre asesinado bajo la tiranía de Arecio González el Tiburón (Cué Fernández, 1989: 414, 416). En suma, la segunda novela del autor cubano resulta una transformación, según a la terminología de Henryk Markiewicz (1988: 260), y, además, una transformación bastante compleja, ya que engloba el tema y el género a la vez. Genette (1997: 56) usa para ello la denominación de ante-texto respecto al texto que resulta la primera versión, un boceto o un borrador del texto final.

La novela Cuando la sangre se parece al fuego se muestra como un texto notablemente amplificado en relación con los ante-textos. Además de las alusiones temáticas y la forma condensada que es la de un cuento, los textos de partida se transforman en una novela en la cual se siguen desarrollando las peripecias del protagonista, Cristino Mora. Por otra parte, uno de los ejes narrativos perteneciente originalmente al hipotexto "Y por última vez", guarda su forma de monólogo. Podemos arriesgarnos a formular la hipótesis de que resulta imposible que el 
receptor polaco descifre estos rasgos intertextuales porque los hipotextos en cuestión no tienen sus versiones polacas.

Algo distinto ocurre con la primera novela de Manuel Cofiño La última mujer y el próximo combate, editada en 1971 en Cuba, galardonada con el prestigioso Premio Casa de las Américas, traducida al polaco por Jadwiga Konieczna-Twardzikowa. El libro apareció en Polonia en 1978, poco después de la traducción de Cuando la sangre se parece al fuego. Así, tenemos que ver con una situación curiosa: la traducción Kiedy krew podobna jest do ognia, precede a la publicación de Ostatnia kobieta, najblizsza walka, escrita en 1971. Lo interesante es que, desde el punto de vista cronológico, La última mujer y el próximo combate relata una historia que ocurrió después de los acontecimientos presentados en Cuando la sangre se parece al fuego. A pesar de que sólo un año separa la publicación de las traducciones, al leer Kiedy krew podobna jest do ognia, el receptor polaco no conoce la novela anterior por no estar aún traducida. Estos hechos nos llevan a la constatación de que, en cuanto a las letras originales, es la primera novela de Cofiño la que constituye el hipotexto para la segunda. En lo que atañe a las traducciones, la situación resulta inversa. Considerados los lapsos en los cuales ambas novelas aparecieron en Polonia, parece poco probable que las traductoras hubieran tomado en consideración las relaciones intertextuales de respectivas traducciones. Por lo tanto, insistimos en el hecho de que, para el receptor polaco, el hipotexto de la versión Kiedy krew podobna jest do ognia (La Habana 1975, Cracovia 1977) es la novela Ostatnia kobieta, najbliższa walka (La Habana 1971, Cracovia 1978). Por otro lado, en el contexto de la falta del acceso al original causada por la distancia lingüística, la capacidad de descifrar los préstamos temáticos por el lector polaco resulta improbable. Sin embargo, en las relaciones intertextuales la más importante es la experiencia literaria individual del receptor, lo "déjà lu" barthesiano. De ahí se desprende que la cronología de la publicación de dichas traducciones no resulte decisiva para la de la recepción por lo que, finalmente, es la novela Ostatnia kobieta, najblizsza walka la que es el hipotexto principal para el receptor polaco.

De todos los préstamos a la novela La última mujer y el próximo combate el sustancial es el que atañe al protagonista Bruno quien aparece también en Cuando la sangre se parece al fuego como un personaje secundario. La primera novela de Cofiño se refiere al año 1965, es decir a los tiempos posteriores al triunfo de la Revolución de 1959, cuando el protagonista trabaja en un plan forestal. De algunas introspecciones el lector sabe que, antes, Bruno era abogado y que se divorció porque no compartía el ideario revolucionario con su esposa Laura. Asimismo, otros fragmentos destacan su lucha a favor de la Revolución. En la segunda novela, el lector conoce la vida de Bruno en la época que precede la victoria de los barbudos, o sea, los revolucionarios del ' 59 .

Encontramos en Cuando la sangre se parece al fuego cinco episodios en los cuales se alude a este personaje secundario. En la primera ocasión, Bruno aparece 
como narrador, relatando su amistad con Cristino $\left(142,102^{1}\right)$. Dado que el texto está escrito en primera persona, el lector no sabe cuál de los personajes de la novela está hablando. Sólo al final, éste menciona que trabaja "en el parque Forestal". Esta característica es el único detalle que remite al personaje de Bruno, pero en este punto de la novela todavía queda indescifrable. En la versión polaca es mencionado "park Leśny".

La segunda mención aparece en el episodio de la introducción de Cristino al grupo de Ângel, activista de la guerrilla urbana:

Allí conocí a Bruno [...]. Bruno era abogado. Una vena enérgica le cruzaba la frente y se le hinchaba cuando hablaba. Laura, la mujer de Bruno era rubia de ojos achinados y con cerquillo; intervenía en todo lo que se decía y me observaba con ojos de desconfianza, sonriendo, con una sonrisa que no me gustó (Cofiño, 1977a: 156).

Dicho fragmento fue traducido de la siguiente manera:

Tam poznałem Bruna [...]. Bruno był adwokatem. Energiczna żyła przebiegała mu przez czoło i nabrzmiewała, kiedy mówil. Laura, żona Bruna, była blondynką o nieco skośnych oczach i nosiła grzywkę; brała udział we wszystkich dyskusjach. Obserwowała mnie oczami nieufnymi, z uśmiechem, który wcale mi się nie podobał (Cofin̄o, 1977b: 112-113).

El fragmento citado, en el cual recibimos más características de Bruno, fue traducido con pequeños cambios sintácticos, sin que éstos afectaran al sentido.

El tercer fragmento es el que resulta el más extenso (por lo que no lo citamos) y, a la vez, el más explícito en cuanto a la relación con el hipotexto $(162,117-118)$. Los elementos que reproduce el texto son numerosos: los personajes (Bruno, Laura y el ingeniero), la situación (el encuentro delante de la tienda "El Encanto", el vestido amarillo limón de Laura, el viaje en el Ford de Bruno), el tema de la conversación (la compra de la nueva casa en Altahabana, las vacaciones en Miami), el comportamiento de los personajes implicados, etc. Resulta que no solamente dichos componentes, sino también varios sintagmas de la descripción son una reproducción mimética. Por eso, enseguida remiten a la forma en la cual aparecen en el hipotexto, hasta los ínfimos detalles (Cofiño 1978: 114-115). Gracias a la traducción literal de Maria Dembowska, este pasaje de la novela es fácilmente descifrable para el receptor.

Sumamente interesante resulta la última frase del pasaje en cuestión: "Między nią i Brunem musiało się zdarzyć to, co się zdarzyło". Sin duda alguna, éste tiene carácter profético, anuncia, en cierta manera, la ruptura de los esposos.

Veamos otro fragmento de Cuando la sangre se parece al fuego:

La represión recrudeció. [...] Bruno y Roli estaban escondidos en casa de un garajista amigo de Agustín. Por medio de un primo de Daniel, que también trabajaba en la concretera, se facilitó la salida de Bruno para la Sierra. Fue a la zona como operador de equipos pesados traducido.

'En primer lugar indicamos el número de la página del texto original y en segundo la del texto 
y a la primera oportunidad se incorporó. Años después, me diría: "Si Laura me viera no me reconocería. Primero abogado, después buldocero, ahora capitân y director de un plan forestal. Ella no podría comprender. La vida da muchas vueltas". Bruno se hizo famoso en las montañas como Pedro el buldoceador (Cofiño 1977a: 196-197).

Maria Dembowska traduce este fragmento de la siguiente manera:

Wzmagały się represje. [...] Bruno i Roli ukrywali się w domu pewnego właściciela stacji naprawy samochodów, przyjaciela Agustina. Za pośrednictwem jakiegoś kuzyna Daniela, który także pracował w fabryce cementu, udało się załatwić wyjazd Bruna w góry Sierra. Zaczął pracować jako maszynista i przy pierwszej okazji przeszedł do partyzantki. Po latach powiedział do mnie: „Gdyby Laura mnie zobaczyła. nie poznałaby mnie. Najpierw adwokat, potem maszynista, a teraz kapitan i dyrektor gospodarstwa leśnego. Ona nie mogłaby tego zrozumieć. Życie przynosi tyle niespodzianek". Bruno stał się sławny w górach jako Pedro, kierow ca buldożera (Cofiño 1977b: 146).

En este pasaje de un párrafo más amplio, se mencionan otros hechos que aluden a la primera novela de Cofiño: la salida de Bruno para la Sierra, el trabajo como conductor-operador, la incorporación a los rebeldes y la lucha revolucionaria. Las características de este personaje son reproducidas explícitamente en Cuando la sangre se parece al fuego y aun más en la traducción de esta novela. El fragmento subrayado, por ejemplo, dice que Bruno "se incorporó" lo que en el contexto verbal ("la salida para la Sierra") alude, evidentemente, a la huida a las montañas donde estaban los rebeldes de Fidel Castro.

En la versión polaca, dicho pasaje resulta mucho más explícito ya que la traductora añade el complemento "do partyzantki" que parece indispensable para que la versión quede más clara. En el hipotexto, en el plano mitológico, se dice justamente que un tal Pedro, que era un nombre cambiado, andaba con los rebeldes y, luego, se fue para la Sierra Grande (Cofiño 1978: 15-16, 21).

Los lexemas subrayados con negrita en el fragmento citado, se refieren a los trabajos de Bruno: operador de equipos pesados y buldocero. En la versión polaca aparece dos veces el nombre de "maszynista" que remite a una profesión parecida, pero no exactamente igual. Además, el sustantivo polaco es asociado con el conductor de trenes por lo que cambia significativamente el sentido. Hay que recalcar que con la profesión de Bruno está relacionado el seudónimo del buldoceador. No obstante, la traducción no subraya esta relación. Mientras tanto, el hipotexto habla de "Pedro od Buldożera" y "Pedro Buldoza", acentuando dicha implicación.

La última cita a la que queremos prestar atención es la siguiente:

A Bruno lo nombraron director de un plan forestal y yo fui a ayudarlo (Cofiño 1977a: 243).

En la traducción dicha frase reza lo siguiente:

Bruno dostał nominację na dyrektora programu zagospodarowania leśnego i pojechałem mu pomóc (Cofiño 1977b: 184). 
El narrador en este fragmento es el propio Cristino. Con el detalle que en él encontramos, el lector puede completar el retrato de Bruno y constatar que el narrador de la primera cita evocada es justamente Bruno. En cuanto a la traducción, de nuevo podemos decir que suena más explícita. La versión polaca es más específica en el sentido de que habla de la repoblación del terreno forestal mientras el original tiene carácter más general.

El propio Manuel Cofiño declaró en una entrevista:

[...] mi universo narrativo a veces se comporta como un todo que se mueve en espiral. Personajes de mis cuentos se entremeten en las novelas, y, como los quiero, no los boto. Además se resisten, quieren estar presentes (Beiro Álvarez, 1989: 394).

Con estas palabras el autor subraya uno de los rasgos principales de su narrativa, el que se manifiesta ampliamente en Cuando la sangre se parece al fuego.

\section{INTERTEXTUALIDAD RESTRINGIDA: AUTOTEMATISMO}

El cambio constituye uno de los ejes ideotemáticos de la novela Cuando la sangre se parece al fuego y un eje principal de toda la obra de Cofiño. El propio autor dice al respecto:

Los objetivos de mi narrativa son tratar de reflejar en la medida de mis posibilidades cómo los hombres no son sólo objeto de la acción del medio, sino tambiên sujetos que actúan sobre el medio y lo cambian; y que, al cambiar el medio, los hombres cambian también a sí mismos (Álvarez, 1986: 103).

Este tema fundamental de la narrativa cofiñana se manifiesta ya en el primer libro de cuentos Tiempo de cambio. Respecto al título, el escritor dijo que así pudiera titularse su obra en totalidad (Álvarez, 1986: 103).

Como confirmación de estas declaraciones escontramos en Kiedy krew podobna jest do ognia múltiples ejemplos que, de manera explícita, hablan de esta vertiente temática. En el cuadro que sigue citamos sólo algunos de ellos:

\begin{tabular}{|c|l|l|}
\hline Núm. & \multicolumn{1}{|c|}{ Cuando la sangre se parece al fuego } & \multicolumn{1}{|c|}{ Kiedy krew podobna jest do ognia } \\
\hline 1 & \multicolumn{1}{|c|}{2} & \multicolumn{1}{c|}{3} \\
\hline 1. & En el cambio de un tiempo dor otro. (21) & W chwili zmiany iednvch czasów na inne. (7) \\
\hline 2. & $\begin{array}{l}\text { Sientes el tiempo, el cambio. La voltereta de } \\
\text { un mundo y de tu vida. Lo viejo que muere y } \\
\text { lo nuevo que ha nacido en ti. (22) }\end{array}$ & $\begin{array}{l}\text { Czujesz czas, zmianę. Zwrot świata i twego ży- } \\
\text { cia. Stare, co umiera, i nowe, co rodzi się w tobie. } \\
(7)\end{array}$ \\
\hline 3. & $\begin{array}{l}\text { Las cosas no serán como han sido. Todo } \\
\text { cambiará. (22) }\end{array}$ & $\begin{array}{l}\text { [...] wszystko będzie inne, nie takie, jak było. } \\
\text { Wszystko się zmieni. (8) }\end{array}$ \\
\hline 4. & $\begin{array}{l}\text { Decirle que ahora es distinto, que todo sería } \\
\text { diferente. que todo ha cambiado. (46) }\end{array}$ & $\begin{array}{l}\text { Powiedzieć jej, że teraz wszystko jest inne, że } \\
\text { wszystko byłoby inne, że wszystko się zmieniło. } \\
(26)\end{array}$ \\
\hline
\end{tabular}




\begin{tabular}{|c|l|l|}
\hline 1 & \multicolumn{1}{|c|}{2} & \multicolumn{1}{|c|}{3} \\
\hline 5. & $\begin{array}{l}\text { Parece que están ahí, con la respiración } \\
\text { contenida. listos para el estremecimiento del } \\
\text { cambio, esperando que esto se convierta en } \\
\text { escombros, en polvo y después en humo, en } \\
\text { amargo humo de recuerdos. (101) }\end{array}$ & $\begin{array}{l}\text { Zdaje się, że są tam, ze wstrzymanym odde- } \\
\text { chem, gotowi do gwaltownej zmiany, czekając } \\
\text { na to, by wszystko przekształciło się w gruzy, } \\
\text { w pył. a potem w gorzki dym wspomnień. (69) }\end{array}$ \\
\hline 6. & $\begin{array}{l}\text { Cómo han cambiado las cosas! Tủ eres otro. } \\
(192)\end{array}$ & $\begin{array}{l}\text { Jakże wszystko się zmieniło! Ty jesteś inny. } \\
(142)\end{array}$ \\
\hline 7. & $\begin{array}{l}\text { Miras las paredes, las ventanas y comprendes } \\
\text { que el tiempo cambia el color de las cosas, } \\
\text { y ventila la vida. (195) }\end{array}$ & $\begin{array}{l}\text { Patrzysz na ściany, na okna i rozumiesz, że czas } \\
\text { zmienia barwę rzeczy i przewiewa życie. (144) }\end{array}$ \\
\hline
\end{tabular}

El texto de la novela está salpicado de referencias autotemáticas. El lector tiene la impresión de que es un motivo obsesivo que va y viene constantemente, que no es solamente una autoalusión, sino un tal dialogismo intratextual, para usar la denominación de Navarro, ejercido por el autor (1986: 149).

En las traducciones de los fragmentos citados se notan interesantes modificaciones estructurales. En el primer caso, por ejemplo, a la palabra clave que es "el cambio", entendido por Cofiño como proceso lo que subraya el sintagma preposicional, acompaña el lexema "chwila" que no tiene nada que ver con el desarrollo implicado por el proceso. En la misma frase el singular del "tiempo" fue sustituido por el plural "czasy" con debidas alteraciones de los determinantes. Esta suerte de modificación gramatical otorga a la frase polaca un tono más natural.

El segundo ejemplo también fue completado en la traducción y alargado para rendir la sintaxis más espontánea. Las frases 4 y 5 , traducidas literalmente, contienen algunas formulaciones malogradas en la versión como, por ejemplo, el condicional en vez del futuro (4), el sintagma "ze wstrzymanym oddechem", o la oración "przekształciło się w gruzy, w pył" (5). En los dos ejemplos se notan huellas de otro texto.

En todos los casos, el juego intertextual consiste en evocar el campo lingüístico del cambio, en subrayar la dicotomía lo viejo-lo nuevo, en asociar lo primero con lo peyorativo y lo segundo con lo positivo; finalmente, en acentuar que este proceso afecta al protagonista Cristino, el hombre que, como lo resume Imeldo Álvarez en su ensayo Sustantividad y carácter en la obra de Manuel Cofiño, "se transforma, avanza y condiciona la naturaleza a sus intereses" (1986: 103).

\section{INTERTEXTUALIDAD INTERNA}

La novela Cuando la sangre se parece al fuego contiene diecinueve viñetas que sirven de trasfondo para la trama. Estos pasajes se refieren a la mitología afrocubana e intercalan los episodios de la narración que, en sí misma, constituye una mezcla de planos espaciales y temporales. Antes de tratar las relaciones inter- 
textuales dentro de la obra y las de su traducción, merece la pena subrayar que las viñetas se pueden tratar como una categoría aparte al considerlas como palabra autoral y metatexto a la vez, que se comporta de manera especial. Así, de un lado, las viñetas se permiten analizar como texto en texto, ya que por su poética y estilo difieren notablemente del resto de la novela. Del otro, estamos convencidos de que forman una parte indisoluble del texto en su totalidad y en este sentido no es posible verlas separadamente. A más, no podemos olvidar el propósito con el que el autor introdujo el plano mitológico a su novela, marcando explícitamente su papel. Todas estas razones nos llevan a la conclusión de que las viñetas deben ser analizadas de manera más compleja, desde, por lo menos, dos perspectivas que se complementan.

Ernesto García Alzola (1989: 65) distingue en la novela cuatro planos: 1) el de los recuerdos, 2) el de la narración principal, 3) el secundario y 4) el mitológico. Para nosotros, los más importantes son el segundo y el cuarto. Las diecinueve viñetas presentan a varios dioses y orishas que están ubicados en sus respectivos momentos de la trama para construir un contrapunteo mitológico para con los personajes y sus acciones. Para un análisis traductológico es muy importante el hecho de que exista una concurrencia entre los personajes de la novela y los orishas afrocubanos que aparecen en las viñetas. En su ensayo Mitología y realidad, dedicado a la novela en cuestión, Mary Cruz cita múltiples ejemplos de estas convergencias que se refieren al carácter, la apariencia, la actitud ante la vida, los hábitos, los atributos, etc. Es evidente, por ejemplo, el lazo entre Cristino y Changó, el orisha que "embruja a las mujeres con zumo de flores de flamboyán ardiente"; el Iazo entre Cristino Mora el padre y Argayú, "dios de los cargadores"; entre la madre Celia Argudín y Yewá, que "tiene una boca triste, y unas sienes tristes y unos dedos más tristes todavía".

En lo que atañe a los personajes secundarios, observamos una práctica semejante, o sea la correspondencia entre Aimé y Yemayá y entre Francilla y Obá. Mucho más sutil resulta el vínculo entre la abuela y Osaín. Estos lazos intertextuales entre el plano mitológico y el de la narración principal, son descifrables, unos más y otros menos, para el lector del texto original. La cuestión que nos proponemos aclarar es si la traducción de algunos de dichos vínculos permite descodificarlos en el texto de llegada.

Una de las conexiones más manifiestas es la que une a Teresa, la hermana de Cristino, con Oshún. En la viñeta dedicada a esta diosa (78-80, 51-52), leemos, entre muchas otras características, que es una "mulata linda, hermosa, gozadora y sandunguera", le gustan el oro, el amarillo, el bronce, la miel, usa cinco manillas de oro, huele a canela. El retrato de Oshún fue reproducido en la traducción con todos los detalles. En Cofiño, unas viñetas preceden y otras siguen las alusiones a orishas lo que facilita establecer vínculos con los personajes, ante todo, los inmediatos. La viñeta que habla de la diosa de las aguas dulces anuncia, de cierta manera, la aparición de un personaje que manifiesta rasgos semejantes. Así, en el capítulo que sigue la viñeta dedicada a Oshún aparece Teresa, ya adolescente y muy cambiada, 
por lo que la coincidencia entre ella y Oshún se impone enseguida al leer este fragmento:

Abuela aseguraba que la mejoría de Teresita se debía a que había hecho santo. "iHiia de Oshún! Es su santa. El destino no se puede torcer. Los santos mandan, imponen y cuando se les hace caso y se les trata bien, ayudan. iHiia de Oshún! Si hasta se parece a ella". Y había que ver a Teresita con sus cinco manillas de bronce, sus collares de cuentas de color miel, como se espolvoreaba canela antes de salir para La Tropical (Cofiño 1977a: 79-80).

El lector polaco recibe la siguiente versión de este fragmento:

Babka zapewniała, że polepszenie stanu Tere należy zawdzięczać świętym. ..Córka Oshuna! To iest jei świeta. Losu nie można zmienić. Święci rozkazują, narzucają ale kiedy dobrze się ich traktuje, pomagają. Córka Oshuna! Nawet iest do niei podobna". I trzeba było widzieć Tere $\mathrm{z}$ jej pięcioma bransoletkami $\mathrm{z}$ brązu, w koralach $\mathrm{z}$ paciorków koloru miodu, jak się pudrowała cynamonem przed wyjściem do „La Tropical” (Cofiño 1977b: 52).

En el original, este fragmento contiene cuatro elementos que aluden a la diosa Oshún: las palabras de la abuela que la evocan explícitamente, y tres características del aspecto de Teresa, las que remiten inmediatamente al retrato de la diosa. La comparación con la versión polaca de Maria Dembowska muestra que sólo la traducción literal de los rasgos físicos permite identificar la nueva imagen de la hermana de Cristino con Oshún. En dicho pasaje, la referencia de la abuela fue distorcionada en el proceso de traducción por el uso del nombre de Oshún como si se tratara de una deidad de género masculino. Esta solución introduce un elemento de otredad prescindible que, además, confunde al lector. Ya la incorporación del panteón afrocubano en la novela constituye, para el receptor polaco, una fuerte manifestación de la cultura del Otro, aumentada artificialmente por la traducción equivocada. A pesar de los cambios que sufre el texto meta, la descodificación de la conexión entre Teresa y Oshún es posible gracias a otras paralelas.

Aparte del ejemplo citado, en el texto polaco hallamos otras referencias a Oshún:

Ach, ci synowie Oshuna! (Cofiño 1977a: 24)

Oby Oshún dał mi swój miód i cynamon. (Cofiño 1977b: 81)

La primera frase es pronunciada por la abuela respecto a una pareja de homosexuales con los cuales trabaja Cristino en la tienda de flores "La Aracalia". La expresión "hijos de Oshún" está vinculada muy estrechamente con el carácter de la diosa que es "voluptuosa", "gozadora y sandunguera". En este ejemplo, sólo la forma del verbo en polaco muestra otra vez que Oshún es una deidad de sexo masculino. Sin embargo, la frase habla de la miel y la canela, dos atributos de Oshún mencionados en la viñeta correspondiente que, esta vez, no precede, sino que se encuentra a continuación. 
A nuestro parecer, este ejemplo produce una confusión más grande que el precedente. El problema es que en la página 123 del texto meta, se encuentra otra descripción de Oshún cuyas características son totalmente diferentes. En el original, encontramos en el mismo lugar la descripción de Osún, el orisha que anuncia la muerte. En consecuencia, a lo largo de la lectura, el receptor polaco tropieza con dos viñetas que hablan de la misma deidad y, paradójicamente, introducen un elemento fuertemente exotizador al texto de llegada.

Los vínculos que Manuel Cofiño compone meticulosamente entre distintas partes de su novela no conciernen solamente a los grandes rasgos de los orishas y los personajes que les corresponden. En el microcosmos de la ficción se establecen varios lazos entre los fenómenos de carácter mitológico que se manifiestan también en el nivel léxico y conciernen a los colores, las especies de fauna y flora y algunos objetos, asociados a los orishas y tratados como sus atributos. Por ejemplo, el orisha Ochosí es amigo del dios que habita el güiro, el detalle que alude a Osaín. En la viñeta dedicada a Osaín se dice que es amigo del dios rojo, una información que remite inmediatamente a Changó. Éste tiene miedo a la diosa del viento y centella, o sea a Yewá. Además, se notan paralelas entre la abuela y Yemayá porque para ambas, el color azul es el de predilección y el identificador, respectivamente. Otros rasgos de la abuela, como el bastón en el que se apoya y la posesión del güiro emplumado, permiten ver analogías con Osaín.

En resumen, los segmentos narrativos se superponen con los mitológicos lo cual constituye un argumento a favor del análisis integral de estos dos planos ya que, evidentemente, tenemos que ver con una expansión semántica dentro de la novela cofiñana.

La conexión entre diferentes planos del texto literario puede manifestarse a través de palabras claves repetidas, enunciados que se refieren a otros enunciados, sútiles acumulaciones de rasgos característicos, construyendo una mise en abyme. Lucien Dällenbach subraya que:

No hay $[. .$.$] que asombrarse de que la función narrativa de toda mise en abyme se caracte-$ rice fundamentalmente por un cúmulo de las propiedades ordinarias de la iteración y del enunciado a la segunda potencia, esto es, la aptitud para dotar a la obra de una estructura fuerte, de asegurar mejor la significancia de la misma, de hacerla dialogar consigo misma y de proveerla de un aparato de autointerpretación (Dällenbach 1997: 89).

La observación de los vínculos internos nos permite constatar que su explicitación en la traducción hace más probable el desciframiento de paralelas entre los planos de la novela. Una fiel reexpresión de ciertos elementos del texto de partida, como los objetos o colores, sobre todo cuando adquieren un rango de símbolos, desempeña un papel muy importante influyendo en la percepción del lector del texto de llegada. Desde luego, tocamos aquí los temas de la manipulación en traducción, la lealtad, la fidelidad y el scopos escogido por los actores del proceso de traducción. Las decisiones tomadas por ellos determinan en gran medida la 
lectura efectuada por el receptor. Omisiones o cambios en la estructura o simbología introducidos en distintas etapas del proceso de traducción deforman la idea previa con la que el autor concibió su obra.

\section{CONCLUSIONES}

Las novelas Cuando la sangre se parece al fuego y La última mujer y el próximo combate de Manuel Cofiño pueden ser tratadas por el lector, tanto el del original como el de la traducción, como dos obras independientes. Si así ocurre, ningún préstamo temático será percibido como tal. Lo mismo puede suceder cuando el lector del texto fuente o el del texto meta se da cuenta de la existencia de ciertas paralelas entre las dos novelas sin ver el eje temático que es el cambio.

Sin embargo, el texto literario constituye una construcción coherente y toda traducción debe reflajarla. La presencia de ejes narrativos que se entremezclan en la primera novela de Cofiño o la de relaciones intertextuales entre la primera y la segunda, forman pilares de esta construcción. Asimismo, la disposición de elementos decidida en el proceso de traducción influye en la percepción del texto meta por parte del receptor de la cultura de llegada. En casos como éste, la consulta de las traducciones de otras obras del mismo autor que ya funcionan en la cultura de llegada, puede resultar importante para identificar o reflejar, si existen, los ejes ideotemáticos de las obras de un escritor dado. Además, la existencia de hipotextos en la lengua término puede sugerir al traductor cómo efectuar su traducción, o sea puede influir en la estrategia que éste emprenderá.

En la mise en abyme podemos observar prospecciones y retrospectivas en el nivel de la novela Cuando la sangre se parece al fuego, y retro-prospectiva en la narrativa cofiña en su totalidad. El hecho de que el lector de la versión polaca de los textos analizados no sea capaz de descifrar todas las relaciones intertextuales, no significa la imposibilidad de entender el sentido de la obra literaria aunque aquellas empobrecieran en el proceso de traducción.

\section{BIBLIOGRAFÍA}

Álvarez I. (1986), "Sustantividad y carácter en la obra de Manuel Cofiño", Revista de Literatura Cubana, núm. 7, julio-diciembre.

Beiro Álvarez L. (1989), "La segunda novela de Cofiño a través de sus dos personajes principales", en: E. García Alzola (ed.), Acerca de Manuel Cofiño, La Habana : Editorial Letras Cubanas.

Cruz M. (1989), “Mitología y realidad" en: E. García Alzola (ed.), Acerca de Manuel Cofiño, La Habana : Editorial Letras Cubanas.

Cué Fernández D. (1989), "Cuando la sangre se parece al fuego: apuntes para una crítica", en: E. García Alzola (ed.), Acerca de Manuel Cofiño, La Habana : Editorial Letras Cubanas. 
Dällenbach L. (1997), "Intertexto y autotexto" en: D. Navarro (ed. y trad.), Intertextualitê. Francia en el origen de un término y el desarrollo de un concepto, La Habana : Criterios.

García Alzola E. (1989), "El realismo poético de Cofiño" en: E. García Alzola (ed.), Acerca de Manuel Cofiño, La Habana : Editorial Letras Cubanas.

Genette G. (1997), "La literatura a la segunda potencia" en: D. Navarso (ed. y trad.), Intertextualité. Francia en el origen de un término y el desarrollo de un concepto, La Habana : Criterios.

Markiewicz H. (1988), "Odmiany intertekstualności”, Ruch Literacki, núm. 169-170.

Navarro D. (1986), "Intertextualidad, canon, juego y realidad histórica en la poesía de Luis Rogelio Nagueras", Revista de la Casa de las Américas, núm. 154.

\section{CORPUS}

Cofiño M. (1977a), Cuando la sangre se parece al fuego, La Habana : Editorial de Arte y Literatura.

Cofiño M. (1977b), Kiedy krew podobna jest do ognia. Trad. de M. Dembowska, Cracovia : Wydawnictwo Literackie.

Cofiño M. (1978), Ostatnia kobieta, najbliższa walka. Trad. de J. Konieczna-Twardzikowa, Cracovia : Wydawnictwo Literackie. 